\title{
Histórico da educação ambiental no âmbito federal da gestão ambiental pública: um panorama da divisão do IBAMA à sua reconstrução no ICMBio
}

\section{History of Environmental Education within Federal Public Environmental Management: an Overview from the Splitting of IBAMA to its Reconstruction in ICMBio}

\author{
Carlos Frederico Bernardo LOUREIRO* \\ Maryane Vieira SAISSE** \\ Cláudia Conceição CUNHA***
}

\begin{abstract}
RESUMO
No presente artigo, resgatamos o histórico da educação ambiental na gestão pública do ambiente, no período compreendido entre a criação do Instituto Chico Mendes de Conservação da Biodiversidade (ICMBio), em 2007, e o momento de institucionalização e consolidação da educação ambiental em seu interior, até o ano de 2012, objetivando demonstrar os aspectos político-ideológicos em disputa no processo de institucionalização do campo em foco em um instituto voltado para a conservação da biodiversidade, após a divisão do IBAMA. Para isso, utilizou-se a análise de documentos oficiais federais e depoimentos de sujeitos protagonistas desse período. Ao final, concluímos afirmando que o processo de consolidação da educação no processo de gestão ambiental no órgão federal, não sem tensões e contradições institucionais, tem se reestruturado, reconstruindo um fazer que foi institucionalmente interrompido no processo de criação do ICMBio e que é fundamental para a luta por justiça ambiental e para a superação da dicotomia conservação-justiça social no Brasil.
\end{abstract}

Palavras-chave: educação no processo de gestão ambiental pública; ICMBio; histórico institucional.

\begin{abstract}
In this article we retrieve the history of environmental education in public environmental management, in the period between the creation of the Chico Mendes Institute for Biodiversity Conservation (ICMBio),
\end{abstract}

\footnotetext{
"Doutor em Serviço Social (UFRJ). Professor da Faculdade de Educação da Universidade Federal do Rio de Janeiro (UFRJ).E-mail: fredericoloureiro89@gmail.com "* Doutora em Psicossociologia de Comunidades e Ecologia Social (UFRJ). Tecnologista sênior do Instituto de Pesquisa Jardim Botânico do Rio de Janeiro. E-mail: msaisse@jbrj.gov.br

*** Doutora em Psicossociologia de Comunidades e Ecologia Social (UFRJ). Analista ambiental no Centro Nacional de Pesquisa e Conservação da Sociobiodiversidade Associada a Povos e Comunidades Tradicionais (CNPT) do Instituto Chico Mendes de Conservação da Biodiversidade (ICMBio). E-mail: cccunha@hotmail.com
} 
in 2007, and the time it institutionalized and consolidated environmental education in 2012, aiming at demonstrating the political and ideological issues in dispute in the process of institutionalization of the field, focusing on an institute dedicated to the conservation of biodiversity after the splitting of IBAMA. For this purpose, we performed the analysis of federal official documents and testimonials from protagonists of that period. Finally, we concluded that the consolidation process of education in the process of environmental management at the federal agency has been restructured, not without tensions and institutional contradictions, rebuilding an activity that was institutionally interrupted in the process of creating the ICMBio, and which is fundamental to the fight for environmental justice and overcoming the social conservation-justice dichotomy in Brazil.

Keywords: education in the process of public environmental management; ICMBio; institutional history.

\section{Introdução}

Conhecer o percurso de institucionalização da educação ambiental na gestão ambiental pública federal ajuda a entender o contexto de sua formação, os pontos de inflexão e como se fizeram presentes no aparelho de Estado os diversos interesses e disputas do campo desde a implantação da política ambiental no país. As diferentes concepções relativas às relações entre sociedade e natureza revelam como, no bojo de um novo projeto de desenvolvimento, a divisão do Instituto Brasileiro de Meio Ambiente e dos Recursos Naturais Renováveis (IBAMA) e a desarticulação de sua Coordenação Geral de Educação Ambiental (CGEAM), junto às alterações no rumo da política ambiental no Brasil, contribuíram para fragmentar (sem conseguir eliminar ou mesmo enfraquecer) a ação educativa de viés crítico, voltada ao fortalecimento da gestão participativa e do controle social das políticas de Estado, que vinha se desenvolvendo na gestão ambiental pública. Como a realidade é dinâmica e contraditória, no mesmo movimento de esfacelamento da educação ambiental nas instâncias ambientais federais do Estado, esta, que veio se configurando desde a criação do IBAMA em 1989, na denominada educação no processo de gestão ambiental pública (QUINTAS, 2005), por meio da ação de seus sujeitos, conseguiu se renovar tanto no IBAMA (por intermédio da ação e normatização da educação ambiental no licenciamento) quanto no Instituto Chico Mendes de Conservação da Biodiversidade (ICMBio).

No presente artigo, por uma questão de recorte do objeto de pesquisa, vamos nos ater estritamente ao histórico ocorrido desde a criação do ICMBio, evidenciando as disputas internas à educação ambiental e entre esta e preservacionistas clássicos que mantêm uma defesa de gestão de UCs (Unidades de Conservação) baseada na separação sociedade-natureza. Resgatar esse processo e clarear os sentidos de educação ambiental é imprescindível para nos posicionarmos a favor de uma ação educativa combativa em tempos de alteração do código florestal e dos limites de áreas protegidas e de mercantilização da natureza. Reconstruir o histórico, resgatando momentos relevantes e fortalecendo a perspectiva crítica e transformadora da educação ambiental é o objetivo principal desse artigo, elaborado com base em documentos oficiais, relatórios institucionais e depoimentos de alguns dos principais sujeitos dessa história. ${ }^{1}$

\section{A fragmentação da gestão ambiental e $o$ apagamento da educação: "Jabuti em cima da árvore? Ou foi enchente ou foi mão de gente” (2007-2010)}

O segundo governo Lula tinha como um dos compromissos assumidos em seu programa o "Aprofunda-

\footnotetext{
${ }^{1}$ Os depoimentos foram prestados em entrevistas realizadas para elaboração da tese: SAISSE, M. Sentidos e práticas da educação ambiental no Brasil: as Unidades de Conservação como campo de disputa. Rio de Janeiro, Tese (Doutorado) - EICOS/UFRJ, 2011
} 
mento do novo modelo de desenvolvimento: crescimento com distribuição de renda e sustentabilidade ambiental". ${ }^{2}$

No entanto, no primeiro semestre de 2007, a rejeição, pelo IBAMA, da licença ambiental prévia ao projeto de construção de duas grandes usinas hidrelétricas no rio Madeira, em Rondônia, alimentou polêmicas em torno dos processos de licenciamentos ambientais no contexto do novo desenvolvimentismo brasileiro (GONÇALVES, 2012). O debate se acirrou sob a pressão para que o órgão ambiental federal concedesse as licenças prévias, abrindo caminho para a licitação das obras. Em 26 de abril, em meio às polêmicas, a ministra do Meio Ambiente divulgou a mudança institucional do MMA e do IBAMA, na contramão da medida que um dia uniu as instituições federais que gerenciavam políticas ambientais, e reconhecia a necessária articulação de ações na gestão ambiental. Foi por meio da Medida Provisória $n^{\circ}$ 366/07 (MP 366/07) que o IBAMA foi desmembrado em duas autarquias, criando-se o Instituto Chico Mendes de Conservação da Biodiversidade (ICMBio), que ficaria responsável pela gestão das Unidades de Conservação. Nessa reconfiguração dos institutos, foram extintas a Diretoria de Desenvolvimento Socioambiental (DISAM) e a Coordenação Geral de Educação Ambiental (CGEAM), e no ICMBio não estava prevista a existência de uma unidade organizacional para a educação ambiental. Em 28 de agosto, é sancionada a Lei 11.516/07, mais conhecida como lei de conversão da MP n. 366/07, que confirmava o conteúdo da MP, mas previa a realização de programas de educação ambiental entre as funções do ICMBio. Houve grande mobilização contra a medida, tanto no âmbito das instituições governamentais quanto em setores da sociedade civil. Os servidores do IBAMA entraram em greve e centenas de pessoas e entidades assinaram um manifesto contrário à referida Medida Provisória, sob o argumento de que ela "prejudica a Educação Ambiental brasileira". Dizia o manifesto:

Reconhecemos, sem medo de errar, que para além de um órgão fiscalizador, os Núcleos de Educação Am- biental (NEA) do IBAMA têm sido aliados políticos de forte envergadura, posicionando-se sob as esteiras de uma plataforma de políticas públicas com seriedade, competência e em amplo processo dialógico com a sociedade civil. ${ }^{3}$

Uma carta, assinada por 70 educadores do IBAMA, tornava públicas as suas posições contrárias à reforma, que entendiam minar a capacidade de o instituto executar as políticas nacionais de meio ambiente conforme o estabelecido na legislação em vigor e se alinhavam ao conjunto dos servidores do IBAMA na luta pela manutenção da integridade das suas atribuições:

A educação ambiental que vimos construindo ao longo da existência do IBAMA pressupõe, para sua efetivação, que seja praticada no contexto das atividades finalísticas do Instituto, tais como: educação ambiental na criação e gestão de UC, na gestão de recursos pesqueiros, no licenciamento ambiental, na proteção e manejo de fauna, na prevenção de desmatamentos e incêndios florestais, etc. Esta prática, exercida coletivamente pelos educadores e demais companheiros de outras áreas do IBAMA, nos ensinou que os instrumentos de gestão ambiental manejados pelo Instituto, no cumprimento de suas atribuições, não são excludentes, mas, sobretudo, complementares. Por tudo isto é que nós, educadores do IBAMA, sempre nos posicionamos pela unicidade da gestão ambiental federal, nos diversos momentos, desde 1991, em que se discutiu a reforma do Instituto. Por outro lado, constatamos que a reforma implementada [...] embora mencione a Educação Ambiental como atribuição de ambos os Institutos, não consta da estrutura organizacional dos mesmos. Neste sentido, nós, educadores da CGEAM, reafirmamos o nosso compromisso com uma educação ambiental crítica, transformadora e emancipatória e conclamamos todos os companheiros a lutarem pela não fragmentação do IBAMA, pela não diluição da Educação Ambiental e pela manutenção da CGEAM na sua estrutura organizacional. Exigimos respeito pelo nosso trabalho, construído ao longo desses anos com competência e compromisso social, com os

\footnotetext{
${ }^{2}$ Lula Presidente. Programa de Governo 2007/2010. Disponível em: <http://bvsms.saude.gov.br/bvs/publicacoes/plano_governo.pdf $>$.

${ }^{3}$ Disponível em: <http://www.xtimeline.com/timeline/Hist--243-ria-da-EA-no-Brasil>. Acesso em: 13/03/2011.
} 
devidos desdobramentos no campo acadêmico e na gestão ambiental pública nacional, bem como repudiamos a terceirização da educação ambiental. ${ }^{4}$

Em reunião ordinária da Comissão Intersetorial de Educação Ambiental do MMA, que reuniu o Departamento de Educação Ambiental do Ministério (DEA) e representantes das instituições vinculadas ao MMA, embora o problema da educação ambiental no IBAMA não estivesse colocado como assunto de pauta, por solicitação de membros da Comissão foi elaborada uma carta a ser entregue à Ministra, pedindo revisão da medida que desestruturou a CGEAM e deixou a educação ambiental sem locus no ICMBio.

O Órgão Gestor da Política Nacional de Educação Ambiental (MMA/MEC), sem a participação de educadores dos dois Institutos, formulou e encaminhou uma proposta à direção do MMA, do ICMBio e do IBAMA, referente à adequação da educação ambiental na estrutura organizacional daqueles institutos com base na transversalidade institucional e na descentralização articulada, que sugeria a criação de uma coordenação geral ligada à Presidência dos órgãos, bem como pontos focais de educação ambiental em cada uma das Diretorias. Pela proposta, também seriam formadas equipes de educação ambiental em instâncias intermediárias - estaduais ou regionais, como no caso dos Núcleos de Educação Ambiental - para apoio das unidades descentralizadas e uma instância colegiada intersetorial constituída pela coordenação geral e pelos pontos focais (GTEA ICMBio/MMA, 2008). Essa proposta se colocava contrária à educação formulada na CGEAM para o processo da gestão ambiental pública, onde se entendia que, para acontecer a transversalidade na estrutura institucional e a sincronia nas ações das representações regionais, seria necessário um planejamento geral que mantivesse a intencionalidade do programa educativo e garantisse os meios para sua implantação.

No relatório de gestão referente ao período 2007/2008, o Órgão Gestor defendeu os avanços obtidos na PNEA e identificou duas lacunas a serem enfrentadas: a primeira relativa à caracterização das institucionalidades para a gestão dessa política e a segunda referente à formação de educadores ambientais. Foi tratada ainda uma possível superposição de atribuições e competências entre o Órgão Gestor e o Comitê Assessor da PNEA e entre a extinta Coordenação Geral de Educação Ambiental do IBAMA e a Câmara Técnica de Educação Ambiental do Conselho Nacional do Meio Ambiente (CONAMA). Em relação à segunda lacuna, identificou-se que não havia na referida política a previsão de instâncias com funções formativas e que a formação de educadores ambientais, no âmbito não formal, devia ser um dos objetos da construção do Sistema Nacional de Educação Ambiental (SISNEA), colocando em questão o significativo investimento na formação de educadores ambientais realizado por mais de duas décadas no IBAMA e, de certa forma, sepultando as expectativas na recondução pela CGEAM, justificada pela criação de um novo Sistema (MMA/DEA, 2009).

O Departamento de Educação Ambiental do MMA continuava com a perspectiva de enraizamento e descentralização da educação ambiental por meio de organizações da sociedade civil, desconsiderando a construção histórica e as conquistas públicas obtidas pela CGEAM e, apesar do esfacelamento da educação ambiental no Ministério, em janeiro de 2003, dos três órgãos vinculados ao MMA, dois possuíam unidades para implementar ações de EA; em 2007, dos cinco órgãos existentes, apenas o Jardim Botânico do Rio de Janeiro continuava a ter uma unidade com essas atribuições.

A busca por transversalizar a educação ambiental, sob uma ótica gerencial de Estado, esvaziando as instituições públicas de setores considerados com atribuições não estritas de Estado, apontava para uma perspectiva pragmática (LAYRARGUES e LIMA, 2011) que se evidenciava no desenvolvimento de projetos dirigidos para a Política e Plano Nacional sobre Mudanças Climáticas, Programa Nacional de Educação Ambiental Portuária e mesmo uma Estratégia Nacional de Comunicação e Educação Ambiental no âmbito do Sistema Nacional de Unidades de Conservação da Natureza.

${ }^{4}$ DE BONI, F. Educação Ambiental, política, participação e a questão socioambiental. 02/05/2007. Disponível em: <http://fabiodeboni.blogs.sapo.pt/7130.html>. Acesso em: 15/12/2010. 
A Ministra Marina Silva se manteve até 2008, quando deixou o Ministério do Meio Ambiente pelo agravamento da oposição à sua agenda dentro do governo. Nessa ocasião, pediram demissão o presidente do IBAMA e o presidente do Instituto Chico Mendes de Conservação da Biodiversidade, também secretário-executivo do Ministério.

Nessa ocasião, já havia sido constituído, por portaria do IBAMA, o Grupo de Trabalho de Educação Ambiental, com a finalidade de propor medidas necessárias à institucionalização e à execução das diretrizes de educação ambiental. O GT atuou em uma situação de estrutura regimental precária no IBAMA, ainda em processo de recondução desde a reforma, e com grande desmobilização do corpo funcional, pois muitos servidores nem mesmo sabiam em qual instituição estariam lotados. O grupo, em uma ação pouco fundamentada em estudos de resultados e atribuições dos servidores públicos que são inerentes à gestão ambiental pública, chegou à conclusão que, para uma prática transversal, deveria ser criada outra estrutura diferente da antiga CGEAM. A estrutura sugerida muito se aproximava da proposta de descentralização articulada encaminhada em setembro de 2007 pelo Órgão Gestor à Ministra e aos diretores dos institutos, com a finalidade, idealmente concebida, de tornar o processo mais "dialógico, horizontal e democrático", tendo como base um colegiado permanente formado por representantes dos NEAs e de cada uma das Diretorias do Instituto ("pontos focais"). Entretanto, educadores do IBAMA que não haviam participado do processo de formulação questionaram a proposta por meio de mensagem encaminhada ao presidente do órgão e ao GT. A mensagem, que apontava lacunas e contradições aos objetivos, rebatia a estrutura fluida, propícia a ações descontextualizadas e privatistas que esvaziavam a institucionalidade pública:

A estrutura proposta dos NEAs, sem uma vinculação orgânica a uma Coordenação Geral e dependentes da vontade política e dos recursos financeiros e orçamentários das diretorias, tenderá a realizar ações pontuais emergenciais emanadas pelas Diretorias, próprias do ativismo, descaracterizando e descontextualizando os NEAs e os processos educativos estruturantes, contradizendo os princípios educativos e conceituais propostos
[...] Quanto ao papel dos NEAs, é importante já indicar a urgência de um espaço ampliado de discussão com propostas construídas regionalmente para serem socializadas, discutidas e deliberadas [...] O princípio da transversalidade não deve se configurar em instâncias como pontos focais em diretorias, mas sim nas diretrizes político-conceituais emanadas de uma Coordenação Geral que pensa e pratica educação no órgão, interagindo com as atribuições próprias deste, a exemplo de como era na extinta CGEAM e como é hoje na DEA no MMA. E reafirmando o documento do encontro da DISAM, subsídio importante reconhecido por este GT, o foco está na Educação no processo de gestão ambiental com um lócus de ação, definido em uma coordenação geral que tem um papel importante na construção de interfaces com as demais diretorias. (ICMBio/MMA - Relatório Encontro Educadores. 2008).

Explicitava-se, assim, projetos distintos para estruturar a educação ambiental na gestão pública relacionados a compreensões diferenciadas sobre o papel da educação no instituto, representatividade e participação que também ficariam evidenciadas no resultado do GT formado, poucos meses depois, no ICMBio (Portaria 116/2008), criado com o mesmo intuito que o GT do IBAMA (ICMBio/MMA, 2008).

Diferente do GT constituído no IBAMA, que se ateve especialmente às medidas de institucionalização da educação ambiental naquele instituto, o grupo criado no ICMBio, o GTEA do ICMBio, formado por representantes do gabinete da presidência e das diretorias, com a finalidade de "propor medidas necessárias à institucionalização e à execução, por esse instituto, das diretrizes da educação ambiental" (Portaria 116/2008), optou por fazer uma "releitura das orientações que regem a educação ambiental brasileira", apresentando no Relatório Final um "exercício síntese de missão, princípios e diretrizes, buscando provocar uma reflexão institucional sobre o papel da educação ambiental no ICMBio" (GTEA ICMBio/MMA, 2008).

Entre os colaboradores externos ao instituto, uma voz dissonante, conforme qualificado no relatório, percebeu a inexistência de um marco orientador e integrador para a educação ambiental neste órgão, o que permitia o desenvolvimento de qualquer expressão de educação ambiental, inclusive as de cunho liberal e privatistas, 
evidenciando o caráter ideológico do uso de um sentido de "público" que comporta tudo (aparentemente democrático, apesar de particularista em suas implicações), sem qualificação no que se refere ao seu sentido universal e igualitário (o que seria efetivamente democrático, buscando a garantia do ambiente como bem comum). Nesse sentido, sugeriu a retomada da proposta original de "Educação no processo de gestão ambiental" para nortear a identidade da ação educativa no instituto e garantir que o conceito de "público" se aplicasse em sua radicalidade democrática (LOUREIRO, 2012).

O relatório do GTEA do ICMBio de fato expressava uma proposta aparentemente democrática, mas que reproduzia uma concepção pautada na conciliação de classes e no esvaziamento do papel do Estado e dos órgãos ambientais sob controle social, assumindo uma orientação político-pedagógica multirreferencial - diferentes formas de ação para a transformação social, frente às diferentes formas de dominação existentes, na qual a conservação da biodiversidade deveria servir de tema gerador "na deflagração de mudanças culturais necessárias ao estabelecimento do novo senso comum emancipatório" (GTEA ICMBio/MMA, 2008).

As diretrizes apresentadas foram construídas paralelamente e em consonância com a Estratégia Nacional de Educação Ambiental (ENCEA), cuja elaboração vinha sendo conduzida pelo DEA (MMA) e à qual a metade dos membros desse GTEA também estava ligada. Para a estrutura organizacional foram oferecidas duas propostas. A primeira sugeria a composição de uma Diretoria de caráter transversal com cargos e pessoal, e a segunda, a criação de uma Coordenação Geral vinculada à Presidência do Instituto e com um processo de educação ambiental em cada macroprocesso ou Diretorias que viessem a ser definidas na estrutura do ICMBio. Foram pensadas ainda estruturas de educação ambiental para as instâncias intermediárias (regionais ou estaduais), com previsão de cargo de assessoramento e existência de um Núcleo de Educação Ambiental em cada unidade descentralizada (UCs e Centros de Pesquisa). Cada estrutura idealmente com um cargo de assessoramento de direção. Um colegiado congregando representantes de todas essas instâncias manteria as ações articuladas, segundo a proposta que desconsiderava assim a mate- rialidade das estruturas institucionais existentes (GTEA ICMBio/MMA, 2008).

Carlos Minc, secretário do Ambiente do Rio de Janeiro, tomou posse como ministro do Meio Ambiente em 2008, com o compromisso de fortalecer a gestão ambiental no país e com a garantia de tornar ágil o licenciamento ambiental de projetos, assegurando, no entanto, maior rigor no processo. Nessa ocasião, os chefes das unidades de conservação federais no Amazonas denunciaram, em manifesto ao Ministério do Meio Ambiente, a situação de abandono e isolamento das áreas que se encontravam sob a responsabilidade do Instituto Chico Mendes. Os gestores das UCs alegavam que a reforma administrativa imposta ao IBAMA tinha gerado uma “competição esquizofrênica" entre a autarquia e o Instituto Chico Mendes por recursos financeiros e humanos, resultando em uma instabilidade institucional.

O Ministro, em setembro daquele ano, nomeou uma nova diretoria para o Departamento de Educação Ambiental do Ministério. Nos institutos foram interrompidos os trabalhos dos GTs com as respectivas propostas de reformulação da educação ambiental. Lucia Anello, diretora da DEA, recebeu apoio dos educadores do IBAMA e do ICMBio, que desejavam ver as diretrizes da educação no processo da gestão ambiental reconduzidas ao Ministério e às instituições vinculadas.

Foi uma gestão de transição, com uma proposta pautada nos objetivos e princípios da Política Nacional de Educação Ambiental, principalmente no que concernia ao fortalecimento dos sistemas de gestão ambiental institucionalizados no país. Nesse sentido, as três principais metas do DEA, nesse período, foram: o fortalecimento do SISNAMA, do SNUC e do SINGREH, fundamentando as ações na estruturação da educação ambiental como política de Estado por meio da atuação na gestão ambiental das atividades poluidoras (licenciamento), das unidades de conservação (UCs) e recursos hídricos (MMA/DEA, 2009).

Ainda de acordo com o relatório apresentado em julho de 2009 das ações que já vinham sendo realizadas no DEA, quase todas foram mantidas. Foram encerrados contratos de consultoria por produto e mantidos aqueles que tinham uma relação direta com as metas assumidas. O orçamento do DEA aprovado para 2009 manteve o mesmo valor do ano anterior, em torno de 1,8 milhão de 
reais. Contudo, o contingenciamento sofrido pelo MMA, somado aos cortes de $60 \%$ sofridos pela SAIC (Secretaria de Articulação Institucional e Cidadania Ambiental), que não teve nenhuma de suas ações escolhidas entre as prioridades do Ministério, resultou em um cenário nunca vivido pela DEA desde a sua criação. $\mathrm{O}$ quadro de pessoal da DEA também sofreu grande abalo por ser em grande parte preenchido por contratos temporários. O setor, que contava com 55 pessoas no início da gestão, chegou em 2009 com 13 técnicos, entre analistas ambientais, terceirizados, estagiários, temporários e consultores. No período, teve destaque a articulação com a Secretaria de Recursos Hídricos e Ambiente Urbano - SRHU/ MMA - e com a Câmara Técnica de Educação, Capacitação, Mobilização Social e Informação em Recursos Hídricos - CTEM, do Conselho Nacional de Recursos Hídricos - CNRH - para estabelecer uma Resolução sobre Educação Ambiental e Mobilização Social no âmbito da gestão das águas.

O principal compromisso da Diretoria do DEA, naquela gestão, foi reconduzir e fortalecer a Educação Ambiental tanto no IBAMA quanto no ICMBio, considerando o que tinha sido construído pelo IBAMA até a Medida Provisória 366/07. Recursos que seriam destinados à realização de oficinas da ENCEA foram redirecionados para possibilitar uma discussão mais aprofundada da Estratégia no âmbito do ICMBio, uma vez que se verificou que a condução até aquele momento não dialogava satisfatoriamente com gestores de UCs e educadores ambientais oriundos das autarquias. Optou-se pela realização do Encontro de Educadores Ambientais do IBAMA e ICMBIO, em dezembro de 2008, com o objetivo de reunir educadores dos dois institutos para troca de experiências e planejamento das ações a serem desenvolvidas com apoio do DEA, além de viabilizar a institucionalização da educação ambiental nos dois institutos, "por demanda expressa do Ministro Carlos Minc, de interagir na busca de uma solução equânime para o problema" (MMA, 2009). O Encontro de Educadores Ambientais do IBAMA e ICMBio teve como finalidade criar um espaço de discussão entre os educadores ambientais dos dois institutos e construir, junto aos dirigen- tes institucionais, estratégias para rearticulação da educação ambiental nas novas arquiteturas organizacionais em construção em ambas as vinculadas. Participaram do evento aproximadamente 90 servidores do IBAMA e do ICMBio e representantes do Departamento de Educação Ambiental do MMA (ICMBio/MMA, 2008).

Inicialmente, um pequeno grupo de educadores ambientais, que representavam as cinco regiões geográficas do país, escolhidos pela representatividade e experiência na área, foram convidados para uma reunião com o objetivo de planejar e dar início ao processo de rearticulação dos educadores e das ações de educação ambiental no âmbito do ICMBio. Para adensar o processo com as bases mais realistas da educação ambiental e seus quadros naquele momento, foi deliberada a realização de um encontro conjunto de educadores ambientais do ICMBio e do IBAMA, com apoio e recursos do DEA/ MMA. Para subsidiar o encontro, foi feito um levantamento, por meio de questionário, para obtenção de informações sobre a situação da educação ambiental nas descentralizadas, o que contribuiria para resgatar o potencial existente e articulá-lo à nova proposta de modelagem institucional.

O diretor da Diretoria de Unidades de Conservação de Uso Sustentável e Populações Tradicionais - DIUSP, à qual se ligaria a educação ambiental no ICMBio, destacou a necessidade de construção de uma proposta de educação ambiental para o ICMBio que considerasse um conjunto de experiências existentes, sendo fundamental um mapeamento dessas ações e de certos cuidados a serem tomados para a elaboração da referida proposta, "tendo clareza de sua Missão Institucional". Destacou que o fato de uma educadora lotada em unidade descentralizada estar coordenando esse processo de rearticulação da educação ambiental no ICMBio indicava o esforço da Diretoria em construir não apenas com quem está na sede em Brasília. ${ }^{5}$

Na discussão que se seguiu, parte da equipe técnica da sede do ICMBio equivocadamente identificou a educação no processo de gestão como "metodologia", o que reflete desconhecimento da mesma e seus fundamentos (QUINTAS, 2005) e argumentou que não havia consenso

${ }^{5}$ O diretor da DIUSP se referia a Laci Santin, responsável pela educação ambiental na Coordenação Regional (CR8) do ICMBio e oriunda do IBAMA. 
sobre a mesma no cenário nacional. Esse grupo ressaltou a necessidade de se introduzir a comunicação associada à educação ambiental, não raramente confundindo-a com o próprio ato pedagógico (LOUREIRO, LAYRARGUES e CASTRO, 2009). Outros participantes apontavam o papel da comunicação no processo educativo como um de seus instrumentos, ou como ação autônoma que a potencializa, não podendo misturar finalidades distintas mesmo que complementares e defendendo corretamente que a educação no processo de gestão não se referia a uma metodologia, mas ao lócus de atuação de educadores na gestão ambiental pública. Apontaram, também, a necessidade de os servidores conhecerem seu papel como gestores públicos, pois esta falta de clareza levava a imprecisões sobre a função da educação ambiental dentro da gestão pública do ambiente e seus instrumentos que materializam a política ambiental e a política de águas no Brasil (ICMBio/MMA, 2008).

Apesar das vitórias obtidas quanto ao amadurecimento das discussões sobre a educação ambiental no instituto, a situação dos educadores ambientais na estrutura do ICMBio era complicada devido à inexistência de unidades análogas aos NEAs do IBAMA. Era preciso pensar em estruturas e canais de interlocução e retroalimentação da sede com os educadores ambientais lotados nas unidades avançadas e centros especializados, onde são executadas, majoritariamente, as ações educativas de competência institucional. Era necessária, ainda, uma maior visão sobre como e quem estava atuando com educação ambiental, pois naquele momento ainda não se tinha o cenário real da área no órgão. Inclusive, muitos educadores que tinham atuado com gestão participativa nas UCs mantinham-se formalmente ligados ao IBAMA à espera de um cenário mais claro no ICMBio.

Nos debates sobre "Educação Ambiental na implantação e implementação da gestão participativa em UCs", foi amplamente discutido o "veto ideológico institucional" em um órgão dirigido por setores preservacionistas e o quanto isso dificultava o exercício da gestão participativa. Considerou-se que o Encontro contribuiu também no sentido de mostrar que, mesmo não sendo hegemônicos, os NEAs vinham construindo e trabalhando com gestão participativa desde a extinta CGEAM/ IBAMA ao desenvolver processos que colaboraram com os setores mais afetados pela injustiça ambiental.
Evidenciava-se naquele encontro que a educação ambiental, estrategicamente posta para atuar no fortalecimento da gestão participativa, enfrentava dois focos de resistência, o primeiro representado pelo preservacionismo clássico, histórico e hegemônico na relação com áreas protegidas, que separa cultura e natureza, imputa à conservação da biodiversidade ausência de pessoas, além de um receituário de gestão técnico-científico. $\mathrm{O}$ segundo foco era, como apontado anteriormente, interno ao campo da educação ambiental e corporificado por tendências identificadas com a ação comunicativa e que abarcava uma multiplicidade de referências e intenções.

$\mathrm{O}$ relatório final daquele encontro de educadores apresentou em suas considerações finais, como sugestão para direção do Ministério, a criação de uma comissão formada por integrantes do DEA e do ICMBio, com representantes dos educadores das regiões, para o planejamento das ações em comum, visando uma melhor interação com o Departamento de Educação Ambiental do MMA que, de acordo com os educadores presentes, além do papel de planejador, agia muitas vezes como executor de ações, algumas sem a necessária internalização pelas UCs.

O relatório final principalmente apontava que a extinção da coordenação geral na sede (CGEAM), a perda da partida orçamentária existente, a dissolução de NEAs em algumas Superintendências e a distribuição dos poucos educadores ambientais capacitados entre as duas instituições geraram novos problemas e intensificaram os antigos.

\footnotetext{
Os obstáculos para o desenvolvimento de ações educativas de longo fôlego decorrem principalmente das indefinições advindas com a criação do ICMBio e do Serviço Florestal e da ausência de uma política institucional que reconheça e incorpore a educação ambiental como um dos instrumentos de gestão ambiental que necessita ser reforçado e integrado, em igualdade de condições, junto aos demais macroprocessos institucionais. Estes obstáculos trazem como consequência uma série de restrições de ordem estrutural comum à maioria das UCs e Centros de Pesquisa, como é a carência crônica de pessoal capacitado, de recursos financeiros, infraestrutura adequada e material informativo sobre as UCs (ICMBio/MMA - Relatório Encontro Educadores. 2008).
} 
Três anos depois, a situação mostrava um quadro ainda mais agravado pela falta de recursos, pela carência de servidores e pela descontinuidade das ações, principalmente as de caráter mais estruturante para a gestão participativa (SAISSE, 2011).

\section{Dez anos da Política Nacional de Educação Ambiental e dois de desinstitucionalização da educação nos órgãos executores da gestão ambiental pública federal (2009)}

Em abril de 2009, comemoraram-se os 10 anos da Política Nacional de Educação Ambiental. A Secretaria de Articulação Institucional e Cidadania Ambiental do MMA e o Grupo de Trabalho de Educação Ambiental da Frente Parlamentar Ambientalista promoveram o Seminário "10 anos da Política Nacional de Educação Ambiental: Avanços e necessidades em busca da edificação de uma sociedade sustentável", com o objetivo de avaliar a implementação da política nesse período e analisar perspectivas futuras.

Além de questões relativas ao financiamento da educação ambiental, a diretoria do DEA reafirmava que um dos pontos que precisavam avançar era a inclusão da educação ambiental nas políticas dos órgãos vinculados ao Ministério do Meio Ambiente: IBAMA, ICMBio, Agência Nacional de Águas e Serviço Florestal Brasileiro.

Em 2009 também seria realizado, na Universidade Federal do Rio de Janeiro, o VI Fórum Brasileiro de Educação Ambiental. O Fórum foi promovido pela Rede Brasileira de Educação Ambiental (REBEA) e pelo Instituto Baía de Guanabara, com recursos do Fundo Estadual de Conservação Ambiental e Desenvolvimento Urbano (FECAM), da Petrobras, do MEC, do MMA, da Secretaria Estadual de Educação, de Furnas, de Itaipu Binacional, do Conselho Federal de Biologia e do Conselho Regional de Engenharia e reuniu cerca de três mil pessoas em mesas-redondas, minicursos, exposição de painéis, oficinas, encontros paralelos e jornadas específicas. ${ }^{6}$
Quando aconteceu esse evento, a diretoria do Departamento de Educação Ambiental do Ministério havia mudado. As responsáveis pelo DEA, no período de setembro de 2008 a 30 de junho de 2009 , se demitiram pouco antes da realização do evento devido à permanência da situação periférica da educação ambiental no Ministério, à falta de resposta aos compromissos assumidos em defesa da reinstitucionalização da educação ambiental no IBAMA e no ICMBio e à falta de recursos e de autonomia nos processos decisórios. ${ }^{7}$ Assumiu o departamento, a convite da secretária de Articulação Institucional e Cidadania Ambiental do Ministério do Meio Ambiente (SAIC), Claudison Rodrigues. O engenheiro foi uma escolha pessoal da secretária e uma tentativa de neutralizar as divergências das duas gestões anteriores do DEA, ao apostar em uma posição menos marcada e de pouca presença na educação ambiental até então.

Trabalhei no ISER, que tem uma área de meio ambiente muito forte, coordenado durante anos pela Samira Crespo. Aí a Samira me convidou, eu larguei tudo e fui pra esse desafio. A primeira vez que vou trabalhar no governo. E quando eu cheguei lá, que já estava instalado, eu descobri que era o Departamento de Educação Ambiental, que era um tremendo abacaxi, né? Todo mundo cobrando, muita demanda e aquela brigalhada toda [...] então, estava um clima terrível. Eu tinha me preparado bem pra assumir, várias pessoas de várias correntes antagônicas da Educação Ambiental, então dei uma boa mapeada nesse terreno e desenvolvi estratégias, que foi devolver a batata quente pra todo mundo [...] chamar todo mundo pra essa realidade e a dificuldade que o campo da EA no Brasil vem passando e dessa brigalhada toda das correntes antagônicas. Convoquei todo mundo a vir se juntar, a integrar essas correntes antagônicas num esforço comum [...] que a gente tá combinando é que para a EA sair desse lodaçal que está, é todo mundo junto [...] além de tudo, a EA tem que se preocupar com o modelo mental, que o que nos faz agir, decidir e tomar decisões não é o acúmulo de conhecimentos, é o nosso psiquismo, são nossas formações psíquicas, então eu venho trazendo muito isso pros debates que eu tenho participado, acho que é uma boa contribuição também que

\footnotetext{
${ }^{6}$ Disponível em: <http://forumearebea.org/>.

${ }^{7}$ Depoimento de Lúcia Anello, ex-diretora do DEA/MMA.
} 
eu estou dando com minha gestão, é trazer essa questão que complexifica a EA e a formação dos educadores. ${ }^{8}$

Nesse período, a educação ambiental nos institutos, IBAMA e ICMBio continuava à deriva. Permanecia com um quadro de servidores identificados com a ação educativa, resistindo com manutenção de trabalhos nas unidades descentralizadas, mas perdendo organicidade na instituição, embora muitas vezes a perspectiva da educação ambiental estivesse presente em outros programas. Durante todo ano de 2009, o processo de consulta pública da ENCEA foi intensificado virtualmente e por meio de oficinas. O Ministério do Meio Ambiente estava determinado a finalizar o processo da consulta para efetivar sua publicação e implementar programas e projetos nas UCs, tendo como norteador o documento final. Um dos entraves para efetivar o processo de implementação era a pouca adesão por parte das Unidades de Conservação Federais, consequência da incipiente institucionalização da educação ambiental no ICMBio e da falta de consenso quanto às diretrizes daquela Estratégia.

Conforme constava no sítio do ICMBio em dezembro de 2009, encontros foram realizados em todas as onze coordenações regionais do ICMBio com o objetivo de divulgar e debater a versão preliminar da Estratégia, que estava em consulta pública desde abril daquele ano no site do ICMBio e ficou disponível até março de 2010.

Oficinas foram demandadas às Coordenações Regionais (CRs) do ICMBio aproveitando espaço e tempo dentro de reuniões de gestores de UCs. As Coordenações chamavam os servidores que sabiam estar trabalhando com educação nas unidades de conservação e esses se articulavam por meio de lista de discussão virtual, buscando apresentar uma perspectiva coletiva para inserção naquele processo. Havia preocupação quanto a avalizar a ENCEA como proposta institucional sem aprofundar a discussão, em um momento no qual não havia uma diretriz institucional para a educação ambiental no ICMBio. Em algumas CRs, no entanto, foi possível, no bojo das discussões, apresentar a proposta dos educadores para a educação ambiental, com ênfase na gestão participativa e sugestões quanto à sua estruturação regional. De acordo com a apresentação feita em 2010, pelo GT responsável pela ENCEA, foram realizados cinco encontros da ENCEA em Coordenações Regionais do ICMBio entre 2009 e 2010.

O relatório de gestão do DEA, no encerramento de 2009, informava que a integração das atividades de EA no MMA tinha sido uma prioridade da gestão, com a qual buscariam evoluir no próximo ano para ações concretas no enfrentamento das mudanças climáticas (MMA/DEA, 2009).

Confirmando um quadro de cortes orçamentários que vinha se agravando desde 2008 , houve contingenciamento e cortes de mais de $60 \%$ no orçamento. Uma emenda parlamentar de bancada no valor de oito milhões de reais, negociada em 2008, não se efetivou. Mudanças ocorreram com o encerramento do período de vigência dos Projetos de Cooperação Técnica (PCT) com a UNESCO e com o PNUD, que viabilizavam algumas iniciativas do DEA e permitiam a contratação de pessoal, o que provocou redução no número de consultores dedicados a alguns assuntos específicos. No entanto, um descontingenciamento de $\mathrm{R} \$ 836$ mil reais oriundos do orçamento da SAIC foi realizado após o VI Fórum Brasileiro de EA, o que recompôs parcialmente os recursos financeiros disponibilizados para o DEA em 2009 (MMA/DEA, 2009).

\section{Estruturação da Coordenação de Educação Ambiental e Capacitação (CEAC) no ICMBio e finalização da Estratégia Nacional de Educação Ambiental e Comunicação (ENCEA) pelo MMA (2009/2010)}

\begin{abstract}
O planejamento de 2010, eu fiz todo em cima do relatório de 2009 [...] para dar continuidade. Algumas coisas novas entraram e a gente está aí tocando as coisas, cheio de dificuldade. Em julho, cinco ou seis funcionários temporários encerram contrato. Várias pessoas vão embora, inclusive o cara que toma conta dos blogs [...] Estamos contratando uns consultores para ir segurando esse segundo semestre, enfim, restrições financeiras, novamente contingenciamento, a gente fazendo parceria
\end{abstract}


[...] sai um monte de gente, gente que tem memória, que tá tocando projeto $[\ldots]^{9}$

O depoimento do Diretor do DEA, no início de 2010, evidenciava as bases frágeis que o Departamento teria para dar continuidade aos seus programas. Ao final daquele período de gestão, alegava ser fundamental para minimizar essas dificuldades uma maior interação entre os gestores da educação ambiental nas vinculadas e o DEA/SAIC/MMA para a definição de linhas de ação, temas orientadores, complementaridade, materiais didáticos, estratégias de implementação, procedimentos para monitoramento e avaliação das ações, entre outros aspectos. Sugeria para isso a constituição de um GT, coordenado pelo DEA, para o qual deveriam estar previstos equipe básica e recursos. A proposta na verdade era uma tentativa de resgate da Comissão Intersetorial de Educação Ambiental - CISEA - que se reuniu até 2007 e foi reeditada pela Portaria 132/2009 sem, no entanto, ser efetivamente implementada, mas que tinha os mesmos objetivos de fortalecer, articular e integrar as ações no MMA (MMA/DEA, 2009).

Dentro desse quadro de esvaziamento dos meios para implementação da educação ambiental na gestão ambiental pública, ainda que consideremos a resistência dos atores que cotidianamente mantinham suas atividades, seja nas sedes, seja nas bases, e das diversas tentativas para rearticular uma educação ambiental mais estruturante nos Institutos, uma iniciativa do Ministério do Meio Ambiente e ICMBio foi crescendo paralelamente visando à mercantilização de algumas categorias de Unidades de Conservação. Em março de 2010, em parceira com o Ministério do Turismo e com o Banco Nacional de Desenvolvimento (BNDES), foi amplamente divulgado na mídia um seminário de incentivo à oportunidade de negócios por meio de concessões de serviços para visitação nos Parques Nacionais Brasileiros. O evento fazia parte do projeto Turismo nos Parques, lançado em 2008, e que se abria a investidores, empresários e representantes de diversas entidades do setor de turismo, reunidos com chefes de unidades de conservação para discutir as possibilidades de estreitamento dos laços entre as unidades e a sociedade, estimulando a visitação por meio do investimento em atividades e serviços turísticos a serem explorados por meio de concessões. Nas palavras do presidente do ICMBio, Rômulo Melo, na abertura do evento: "Não se trata de privatizar os parques nacionais, mas apenas direcionar para esse setor a administração da questão turística. A conservação e a fiscalização seguem sob responsabilidade da União..."10

Fazia-se revelar o que o governo, o Ministério e o ICMBio entendiam ser necessário para aproximar a sociedade das unidades de conservação, a que objetivos de "modernização" dos parques seriam destinados créditos do BNDES e o foco dado à potencialidade de lazer e aventura de unidades de conservação que tivessem perfil para isso.

Ainda ao final daquele, mês assumiu a nova ministra do Meio Ambiente, Izabella Teixeira, que sucederia Carlos Minc em seu final de gestão. A ministra fez carreira no IBAMA e foi secretária-executiva do Ministério de Minc. Assim, foram mantidas a secretaria da SAIC - Secretaria de Articulação Institucional e Cidadania Ambiental - e a diretoria do Departamento de Educação Ambiental do Ministério. Em setembro daquele ano, era divulgado um levantamento da assessoria parlamentar da presidência de ICMBio referente à tramitação de 11 projetos de lei com o objetivo de reduzir as unidades de conservação ambiental criadas pelo governo federal e localizadas na Amazônia, Cerrado e Mata Atlântica, além de outros quatro textos que tramitavam no Legislativo pondo em xeque o Sistema Nacional de Unidades de Conservação (SNUC). O levantamento, realizado pelo ICMBio, apontava pressão econômica em áreas do Pará, Rondônia, Roraima, Maranhão, Bahia, Minas Gerais, Espírito Santo, Paraná e Santa Catarina. Se aprovados, os textos retirariam a proteção de milhares de hectares de florestas nativas, na maioria dos casos beneficiando o agronegócio, pecuaristas e mineradoras.

A pressão ocorria em dois sentidos: pelo redesenho dos limites geográficos e pela alteração de status da unidade, transformando áreas de proteção integral em de uso sustentável, que presumiam algum tipo de atividade econômica. O que poderia significar um saldo

\footnotetext{
${ }^{9}$ Depoimento de Claudisson Rodrigues, diretor do DEA entre 2009 e 2011.

${ }^{10}$ Turismo nos parques. Disponível em: <http://parnatijuca.blogspot.com/2010_03_01_archive.html >. Acesso em: 15/03/2010.
} 
positivo, na troca por áreas protegidas mais inclusivas da população e do uso sustentável dos recursos naturais, revelava casos especialmente graves de atendimentos a interesses privados. Dois diziam respeito ao Parque Nacional da Serra da Canastra (MG): reduzir a Canastra em 47 mil hectares e tornar a parte desanexada da categoria atual de proteção integral para área passível de ocupação. O terceiro caso envolvia a Floresta Nacional do Jamanxim (PA), que corria o risco de perder quase $80 \%$ de seu território e envolvia interesses econômicos e políticos gigantescos. ${ }^{11}$

As Unidades envolvidas em tais projetos ficaram ao largo dessas discussões. Quais interesses estavam tramitando com eles? Que meios havia para interferir, para expor os projetos contrários? É certo que se alguns desses projetos obtivessem êxito constrangeriam interesses da conservação e de seus defensores, bem como de diversos grupos sociais que de alguma forma ocupassem esses territórios. O que fazer diante de uma gestão ambiental pública fragilizada, atuando com um quadro pessoal insuficiente, de pouca força política, na qual os instrumentos de gestão participativa que podiam resultar em nova força de resistência operavam no limite, no caso dos poucos conselhos gestores atuantes naquela ocasião? Por que os tradicionais defensores da preservação não usavam o combativo enfoque com que costumavam aparecer na mídia contra as populações que manifestavam seus direitos pela moradia e uso de recursos naturais junto às áreas protegidas por lei? Como realizar um mapeamento dos grupos de interesses e residentes, como orientar e mobilizar os grupos residentes envolvidos com essas Unidades, o que poderia ser estratégico para uma educação ambiental de fato estruturante?

Ao final de 2010, um relatório do DEA/MMA descrevia o estado lamentável da educação ambiental no Ministério e nas vinculadas e os processos de reinstitucionalização no ICMBio e IBAMA. Das cinco instituições vinculadas ao Ministério do Meio Ambiente, apenas o Jardim Botânico do Rio de Janeiro permanecia com a educação ambiental institucionalizada como Serviço de Educação Ambiental, vinculado à Diretoria de Ambiente e Tecnologia, e mantinha equipe e recursos. A Agência Nacional de Águas e o Serviço Florestal Brasileiro, apesar de desenvolverem ações com capacitação e informação, nunca chegaram a constituir uma área planejada para a educação. De acordo com o DEA,

\begin{abstract}
A EA no IBAMA tem estado associada à Educação Corporativa e alocada na DIQUA. Em 2010, a Diretoria solicitou relatórios dessas atividades e 23 Estados responderam, revelando que, apesar de a EA não estar institucionalizada no IBAMA, as unidades descentralizadas e a Sede continuam atuantes, pressionadas pelas demandas crescentes da sociedade e pelo compromisso das equipes [...] No ICMBio está proposta uma Coordenação específica, inserida na Gerência de Gestão Socioambiental; essa proposta está na Casa Civil e não foi efetivada. Entretanto e na prática, há um Coordenador de EA e Capacitação, com equipe mínima e recente, que precisam ser fortalecidos. Há grande carência de servidores e necessidade de capacitação para formar um corpo de educadores ambientais no ICMBio (MMA/ DEA, 2010).
\end{abstract}

Na realidade, até o final de setembro daquele ano, a agenda da educação ambiental e da gestão participativa foi conduzida por uma mesma coordenação. O Instituto continuava sem ter oficializado a nova estrutura e com algumas atividades em fase de transição quando foi nomeado, pela Portaria n. 461/2010, o responsável pela Coordenação de Educação Ambiental e Capacitação. Felipe Mendonça havia atuado com Reserva Extrativista no Acre e tinha experiência com gestão participativa.

Entre as diversas demandas, destacavam-se o encaminhamento interno da ENCEA e a reorganização da educação ambiental, que nas unidades descentralizadas caminhava com diferentes condições e estrutura para a ação educativa. Foi decidido um encontro com os educadores das descentralizadas - coordenadorias regionais, unidades de conservação e centros de pesquisas - no qual pudessem ser discutidas tanto a ENCEA quanto a estrutura e o planejamento da educação ambiental no instituto. Aproveitando os recursos disponíveis, o evento

\footnotetext{
${ }^{11}$ Disponível em: <www.valoronline.com.br>. Acesso em: 06/09/2010 e com base no "Levantamento para fins de acompanhamento das proposições que alteram áreas de UCs" (Relatório interno, não publicado e obtido por troca de correspondência com Assessoria da Presidência do ICMBio).
} 
foi realizado no espaço para formação do ICMBio (ACADEBIO), com duração de três dias e a oficina da ENCEA teve a participação de pessoas externas ao instituto. $\mathrm{O}$ encontro dos educadores se estendeu pelo terceiro dia e contou com participação do diretor e coordenadores do ICMBio de maior envolvimento com a educação ambiental. Uma circunstância a ser destacada é que nas mesmas datas e no mesmo local acontecia parte do módulo "gestão de conflitos socioambientais" do ciclo de capacitação em gestão participativa destinado a gestores, com o perfil e objetivo de "promover a reflexão da prática da gestão ambiental pública frente aos conflitos socioambientais a partir da ótica da gestão participativa, subsidiando o desenvolvimento de ações intrínsecas no processo de mediação/resolução de conflitos socioambientais". Ele tinha em seu corpo de planejadores e instrutores diversos agentes que, desde o IBAMA, apresentavam reconhecida atuação com a educação ambiental e que, devido à sobreposição dos eventos, não puderam participar das discussões do encontro, a não ser em rápidas situações que agregavam todo o grupo.

A oficina final de consulta da Estratégia Nacional de Comunicação e Educação Ambiental no âmbito do SNUC-ENCEA foi realizada em conjunto com o DEA/ MMA na intenção de ser o último momento de construção do documento. Teve a participação, em média, de 45 pessoas, entre gestores e/ou responsáveis pela educação ambiental das UCs federais e centros especializados, selecionados a partir das Coordenações Regionais e dos respectivos centros. Foram convidadas a participar pessoas de fora da instituição que tivessem atuação com educação e unidades de conservação.

A oficina foi considerada produtiva pelos participantes e, por causa do momento de reconstrução da educação no ICMBio, a iniciativa foi entendida, em certa medida, como reconhecimento da importância dos agentes que pertenciam à instituição e que estavam na "ponta" da construção de diretrizes e programas educativos.

O Encontro para o Planejamento e Estruturação da Coordenação de Educação Ambiental e Capacitação (CEAC) aconteceu junto à oficina e teve como objetivos resgatar o histórico e apresentar o momento atual da educação ambiental na estrutura do ICMBio e definir uma proposta de escopo para a coordenação com prioridades e estratégias para 2011.
Nas discussões com representantes da diretoria do instituto, evidenciou-se a equivalência entre esse macroprocesso e as atribuições da antiga CGEAM no IBAMA. Propostas para capacitação de servidores foram encaminhadas ao Plano Anual de Capacitação (PAC) do Instituto para 2011, contemplando algumas das reivindicações dos participantes: introdução à questão indígena $\mathrm{e}$ quilombola na gestão de UCs, elaboração e implementação de termos de compromisso para população residente em UC de proteção integral, ciclo de gestão participativa, ferramentas e técnicas participativas, curso de educação ambiental em unidades de conservação com foco no controle social, sob premissas da justiça ambiental.

Para construir uma proposta de escopo para a CEAC, foi realizada discussão por grupos, considerando a questão: "Quais seriam as atribuições e interfaces da Coordenação de Educação Ambiental e Capacitação dentro dessa nova estrutura do Instituto Chico Mendes?".

Desse trabalho foram definidos sete grandes temas que seriam de responsabilidade da CEAC conduzir dentro do ICMBio: Capacitação externa; Mapeamento de Educadores Ambientais/Estabelecimento de uma Rede de Educadores/Sistematização das experiências; Apoio técnico e financeiro a projetos; Produção de material educativo/Divulgação das UCs; Relações inter e intrainstitucional; Elaboração de projetos político-pedagógicos; e Capacitação Interna.

A reunião de planejamento e estruturação da Coordenação de Educação Ambiental e Capacitação foi o início de um importante exercício de participação conjunta na estruturação da CEAC, que pretende se estender ao longo do ano de 2011 [...] No encontro, ainda é bastante visível a confusão que se faz sobre o papel da Educação Ambiental nos diversos processos do ICMBio [...] pensar uma "nova Educação Ambiental" ainda causa alguma estranheza. No entanto, é pertinente ressaltar a vontade dos presentes em começar a traçar esse novo caminho da Educação Ambiental (dentro ou não da CEAC), buscando entender como ela pode se fazer efetiva ao longo de todos os processos do Instituto e na sua nova estrutura pensada (ICMBio/MMA, 2010, não paginado).

$\mathrm{O}$ que fosse acontecer a partir desse marco iria depender da conjugação de forças internas do Instituto 
Chico Mendes de Conservação da Biodiversidade, das demandas e pressões do conjunto de educadores ambientais e das populações atingidas pela gestão das UCs e, ainda, do quadro futuro de um governo que mudaria no ano seguinte e que, ao que tudo indicava (e se confirmou), com poucos compromissos com a causa ambiental que busca conservação com justiça social, adotando um desenvolvimentismo que agrava a pressão sobre recursos naturais e amplia a expropriação do trabalho. Fora dado um passo importante na recondução da educação ambiental dentro da instituição, principalmente se considerarmos a perpetuação do esvaziamento institucional nas demais vinculadas do MMA e admitindo que há a ampliação de ações que materializam a proposta de educação no processo de gestão ambiental pública no licenciamento e na gestão de águas.

Foi considerada, como parte importante nesse processo, a estratégia que vinha sendo realizada desde a CGEAM/IBAMA, cujo foco estava no controle social de políticas públicas, mobilização de grupos sociais tradicionais e em situação de vulnerabilidade para a ocupação de espaços públicos do sistema de gestão ambiental e que tinha trazido para seu exercício o princípio participativo e a construção do ambiente como bem comum, tão caros à educação ambiental.

\section{Implementação da Coordenação de Educação Ambiental no ICMBio e retomada dos processos formativos em Educação Ambiental (2011/2012)}

O encontro para o planejamento e estruturação da Coordenação de Educação Ambiental e Capacitação Externa (CEAC) do ICMBio, realizado em novembro de 2010, definiu como prioridades para o processo de estruturação dessa Coordenação as seguintes ações:

1) Mapeamento de educadores para estabelecer uma rede; 2) sistematização e divulgação de experiências de educação ambiental dentro do Instituto; 3) estabelecimento de um calendário de encontros de educadores; 4) estabelecimento de um colegiado para ajudar a elaborar e apoiar a estruturação da CEAC; 5) capacitação em EA dos servidores; 6) estabelecimento de um programa de capacitação externa; e 7) buscar estabelecer as articulações internas (ICMBio/MMA, 2010, não paginado).

Aqui, pretendemos analisar algumas dessas ações rumo à implementação da CEAC. Como essas estratégias se materializaram no âmbito do Instituto Chico Mendes nos dois anos seguintes?

Uma das deliberações do encontro de educadores em 2010 havia sido a estruturação de um Colegiado de educação ambiental que deveria ajudar a elaborar e apoiar a estruturação da CEAC. Esse grupo iniciou sua existência informalmente, reunindo pessoas que haviam sido indicadas no próprio Encontro e outras que foram inseridas no sentido de contemplar a representação das diferentes coordenações regionais do ICMBio, a despeito do que foi definido no Encontro. Exceto a participação por $e$-mail em ações pontuais ou a colaboração individual de membros do Colegiado no atendimento a demandas específicas, não foi feita a inserção desse colegiado na estruturação da Educação Ambiental do ICMBio de forma coletiva e organizada. Até o final de 2012, sua formalização não ocorreu, o que impede a discussão mais concreta sobre qual papel realmente viria a assumir no Instituto. E, mais importante, não se realizou a discussão sobre as diretrizes a serem assumidas pela Coordenação e pela Educação Ambiental no Instituto.

Entretanto, dois outros encaminhamentos iniciaram a estruturação para a questão "qual Educação Ambiental se quer para o instituto Chico Mendes?". Uma delas foi a "Chamada para apresentação de Projetos de Educação Ambiental e Capacitação Externa” (ICMBio, 2011a), cujo edital foi publicado em janeiro de 2011 e recebeu 82 propostas de projetos nas temáticas: a) capacitação externa; b) sensibilização e mobilização social; e c) Produção de material educativo e/ou divulgação. Destes, dezessete projetos foram aprovados com financiamento da $\mathrm{COEDU}^{12}$ e quatro com financiamento do Projeto PNUD. Oito projetos foram aprovados sob

\footnotetext{
${ }^{12}$ Como fruto do processo de modelagem institucional do Instituto Chico Mendes, a Coordenação de Educação Ambiental e Capacitação Externa - CEAC - passou a se chamar Coordenação de Educação Ambiental - COEDU.
} 
condição de reformulação (ICMBio, 2011b). O número expressivo de projetos apresentados nessa chamada explicita a carência para apoio a essa temática no Instituto e a demanda reprimida entre educadores e gestores a esse respeito. De fato, com a organização do ICMBio em macroprocessos e, ao mesmo tempo, a diluição dos fazeres da educação ambiental em outras coordenações (gestão participativa, gestão de conflitos), essa foi a primeira vez que o Instituto denominava práticas que estariam sendo financiadas a partir da educação ambiental e, com isso, disponibilizava dotação orçamentária específica para tal (FONTANA et al., 2011).

Uma segunda ação procurou resgatar o processo formativo que havia sido um dos principais pilares da extinta CGEAM: os cursos de Introdução à Educação no processo de gestão ambiental. Sob a coordenação da CGEAM, no IBAMA, foram realizados 24 cursos, no período de 1997 a 2006, com a participação de educadores do IBAMA e de outras instituições públicas e da sociedade civil, em um processo consolidado de formação que, após a criação do ICMBio, em 2007, não teve continuidade enquanto política institucional em nenhum dos dois órgãos. ${ }^{13}$

Em 2011, sob a coordenação pedagógica de José da Silva Quintas (contratado por meio do edital PNUD 001/2011, de 18/05/2011), estruturou-se e ministrou-se o "Curso de Educação Ambiental na Gestão Pública da Biodiversidade", cujo corpo docente foi formado por educadores de diferentes Unidades do ICMBio e proposta político-pedagógica calcada na Educação no Processo de Gestão Ambiental. Além do escopo do curso voltado à conservação da biodiversidade, esse curso ainda apresentou um importante diferencial em relação aos cursos ministrados pela extinta CGEAM: os educandos deveriam formular projetos de intervenção, na forma de cursos de aplicação prática, por meio dos quais, com recursos alocados para tal, deveriam produzir cursos no âmbito da gestão ambiental pública em seus locais de inserção. Foram 45 educandos, dentre servidores do Instituto e atores sociais que se relacionavam com as Reservas Extrativistas (Resex) de determinados recor- tes territoriais. $\mathrm{O}$ objetivo era incentivar a articulação territorial e envolver lideranças de Resex na construção do curso nos diferentes recortes. Essa diferença seria fundamental para contribuir com processos formativos em diferentes unidades do país, comprometidos com a intervenção social na gestão ambiental pública, uma vez que um gargalo enfrentado pela Coordenação Geral de Educação Ambiental no IBAMA residia no financiamento das ações educativas.

Porém, até o final de 2012, dos projetos que deveriam ser elaborados e implementados pelos cursistas, apenas um (no recorte territorial do babaçual maranhense) foi finalizado. As causas para essa pouca implementação foram variadas, envolvendo a falta de um acompanhamento mais efetivo por parte da Coordenação Central que respaldasse os esforços de mobilização/ incentivo para essa finalização e potencializadas por um corte financeiro ocorrido no primeiro semestre de 2012, que impossibilitou a realização de alguns cursos em plena fase final de elaboração. Em outubro de 2012, deu-se início à segunda edição do curso de Educação Ambiental na Gestão Pública da Biodiversidade, ainda com o comprometimento de operacionalizar ações de intervenção educativa locais. Entende-se que o fortalecimento de ações formativas para a formação de educadores ambientais é estruturante para a consolidação da temática no instituto. No entanto, a realização de um curso desse porte, sem a presença de uma equipe destinada exclusivamente para sua operacionalização, é um desafio que será necessário enfrentar.

É válido salientar que durante o ano de 2011 outro fato parece ter contribuído para a pouca implementação dos acordos obtidos na oficina de educadores. No período de fevereiro a julho de 2011, novamente a Coordenação de Educação Ambiental ficou sem um titular exclusivo para a temática. Felipe Mendonça acumulou as coordenações de Educação Ambiental e Gestão Participativa até julho de 2011, quando passou a assumir definitivamente a Coordenação de Gestão Participativa (CGP). Após esse período, a Coordenação de Educação Ambiental ficou sob a responsabilidade de Fabiana Prado, cuja aproxi-

\footnotetext{
${ }^{13}$ No âmbito do IBAMA, ainda ocorreram alguns cursos com esse escopo, atendendo a demandas específicas e articulações locais que permitiam sua realização.
} 
mação com o Instituto havia se fortalecido no "Projeto de Capacitação em Gestão Participativa de Unidades de Conservação", realizado no biênio 2007/2009, no âmbito do Programa Demonstrativo PDA - Mata Atlântica/Ministério do Meio Ambiente - PDA/MMA, e executado conjuntamente pelo IBAMA (por intermédio de seus Núcleos de Educação Ambiental nos Estados de Santa Catarina, Paraná, Rio Grande do Sul e Mato Grosso do Sul $)^{14}$ e a ONG Mater Natura, da qual Fabiana Prado fazia parte. Essas mudanças contribuíram para uma maior lentidão no encaminhamento das demandas acordadas no Encontro realizado em 2010.

\section{Considerações finais}

A despeito de um grande avanço em direção à institucionalização da educação ambiental no Instituto Chico Mendes de Conservação da Biodiversidade, após todo um momento de desmonte, observa-se que a falta de clareza institucional das diretrizes assumidas pela

\section{Referências}

FONTANA, A. et al. O resgate da educação ambiental na gestão pública da biodiversidade - a estruturação da educação ambiental no ICMBio. In: FÓRUM BRASILEIRO DE EDUCAÇÃO AMBIENTAL, 7., 2011. Salvador. Anais.

GONÇALVES, R. Novo desenvolvimentismo e liberalismo enraizado. Serviço Social e Sociedade, São Paulo, n. 112, out./dez. 2012.

GTEA ICMBio/MMA. Relatório final Grupo de Trabalho de Educação Ambiental (GTEA/ PORTARIA 116/2008). Brasília, 2008.

INSTITUTO BRASILEIRO DO MEIO AMBIENTE E DOS RECURSOS NATURAIS RENOVÁVEIS - IBAMA Relatório do Grupo de Trabalho de Educação Ambiental. Brasília, 2008.

ICMBio/MMA. Relatório final: Encontro de Educadores Ambientais do Instituto Chico Mendes de Conservação da Biodi-
Coordenação de Educação Ambiental fragiliza a adoção de estratégias que possam pautar a educação ambiental como estratégica na consolidação da participação social e promoção da justiça ambiental no âmbito da conservação de biodiversidade. Entretanto, a reunião de educadores com histórico e comprometimento com uma educação ambiental crítica e emancipatória, nas diferentes tentativas de estruturação da educação ambiental no Instituto, demonstra a intenção de se consolidar internamente um direcionamento público na gestão de unidades de conservação e a capacidade de articulação e mobilização desses educadores em direção a essa institucionalização.

Por outro lado, por mais significativo que seja este processo instituído pelos educadores do Instituto, a ausência de uma coordenação geral na Sede, com corpo funcional que viabilize as demandas vindas das Unidades Descentralizadas e, ao mesmo tempo, atue como instância gestora, aglutinadora e política na definição de prioridades e no respaldo para que os educadores possam desenvolver suas atividades, é um desafio que se coloca ao ICMBio. versidade (ICMBIO) e do Instituto Brasileiro do Meio Ambiente e Recursos Naturais Renováveis (IBAMA). Brasília, 2008.

ICMBio/MMA. Relatório do Encontro para o planejamento e estruturação da Coordenação de Educação Ambiental e Capacitação (CEAC). São Paulo, 2010.

ICMBio. Chamada de projetos de educação ambiental. Disponível em: <www4.icmbio.gov.br/intranet/download/ arquivos/anexos/Chamada_de_Projetos_EA.pdf $>$. Acesso em: 02/02/2011. Brasília, 2011a.

ICMBio. Memo. Circ. $n^{\circ}$ 05/2011 - CGP/CGREX/DIUSP/ ICMBio, de 15 de abril de 2011. Publica o resultado da chamada de projetos para educação ambiental e capacitação externa. Brasília, 2011b.

LAYRARGUES, P. P.; LIMA, G. F. da C. Mapeando as macrotendências político-pedagógicas da educação ambiental con-

${ }^{14}$ Após a divisão do IBAMA, em 2007, o Projeto passou a ser assumido pelo ICMBio. 
temporânea no Brasil. In: ENCONTRO DE PESQUISA EM EDUCAÇÃO AMBIENTAL, 6., 2011. Ribeirão Preto. Anais.

LOUREIRO, C. F. B. Sustentabilidade e educação: um olhar da ecologia política. São Paulo: Cortez, 2012.

; LAYRARGUES, P. P.; CASTRO, R. S. de (Orgs.). Repensar a educação ambiental: um olhar crítico. São Paulo: Cortez, 2009.

MINISTÉRIO DO MEIO AMBIENTE. Diretoria de Educação Ambiental. Relatório de transição do Departamento de Educação Ambiental do MMA (2008/2009). Brasília. MMA, 2009.
. Diretoria de Educação Ambiental. Estratégia $\mathrm{Na}$ cional de Educação Ambiental. Versão final. Disponível em: $<$ http://encea.blogspot.com/>, <www.mma.gov.br $>$. Acesso em: 15/04/2011.

QUINTAS, J. Como o IBAMA exerce a educação ambiental. Brasília: IBAMA, 2005.

SAISSE M. V. Sentidos e práticas da educação ambiental no Brasil: as unidades de conservação como campo de disputa. Rio de Janeiro. Tese (Doutorado) - Universidade Federal do Rio de Janeiro, Instituto de Psicologia, Programa de Pós-Graduação em Psicossociologia de Comunidades e Ecologia Social - EICOS, 2011.

Recebido em 13 de dezembro de 2012. Aceito em 01 de novembro de 2013. Publicado em dezembro de 2013. 